\title{
Metodologia para determinar a viabilidade de tubérculos de Cyperus rotundus
}

\author{
Methodology for determining the tubers viability of Cyperus rotundus
}

\author{
Ferdinando Marcos Lima Silva ${ }^{1}$, Edivaldo Domingues Velini ${ }^{2}$, Caio Vitagliano Santi Rossi ${ }^{3}$, \\ Eduardo Negrisoli ${ }^{4}$, Marcelo Rocha Corrêa ${ }^{4}$
}

Resumo - Este trabalho teve como objetivo desenvolver e validar uma metodologia fundamentada no uso de tetrazólio para determinar a viabilidade de tubérculos de tiririca (Cyperus rotundus). Os tratamentos para o desenvolvimento da metodologia foram combinados em esquema fatorial $3 \times 4 \times 5$, sendo 3 condições de tubérculos (mortos como testemunha, condicionamento com água e para perda de umidade); 4 concentrações de tetrazólio $(0,1 ; 0,25$; $0,5$; e $1 \%)$; e 5 períodos de avaliação $(8,16,24,32$ e 48 horas após imersão na solução). Para a validação da metodologia, os tratamentos foram combinados em esquema fatorial $2 \times 5$, sendo 2 métodos para avaliação dos tubérculos (teste de tetrazólio e brotação) e 5 doses de glyphosate: 0 , 180, 360, 720 e $1440 \mathrm{~g}$ e.a. ha ${ }^{-1}$, aplicado sobre $C$. rotudus no estádio de pré-florescimento. Aos 30 dias após a aplicação do glyphosate os tubérculos foram coletados para as avaliações pelos testes de tetrazólio e brotação. A concentração de tetrazólio utilizado para validação foi de $1 \%$, mantendo os tubérculos na solução por um período de 24 horas. Ao término de cada período estudado os tubérculos foram retirados, lavados e cortados para proceder a avaliação visual, determinando a presença e intensidade de coloração ao longo da superfície dos mesmos. Os melhores tratamentos foram aqueles nos quais os tubérculos foram previamente desidratados, indicando que a entrada do tetrazólio ocorre predominantemente por fluxo de massa. Os resultados dos tratamentos para validação da metodologia indicaram que a porcentagem de coloração foi decrescente em resposta ao aumento da dose de glyphosate. O teste de tetrazólio é um bom indicador da viabilidade de tubérculos de tiririca, com resultados satisfatórios quando imersos em solução de $1 \%$ de concentração por no mínimo 8 horas.

Palavras-chave: Planta daninha, tetrazólio, tiririca.

\begin{abstract}
This work aimed to develop and to validate a methodology based on tetrazolium test to determine the viability of purple nutsedge tubers (Cyperus rotundus). The treatments for methodology development were combined in factorial design $3 \times 4 \times 5$, three tubers conditions (dead as control, conditioning with water and conditioning for loss of moisture), four concentrations of tetrazolium $(0.1,0.25,0.5$, and $1 \%)$ and 5 assessment periods $(8,16,24,32$ and 48 hours after immersion in solution). For methodology validation the treatments were arranged in factorial design $2 \times 5$, with two methods to evaluate the tubers (tetrazolium test and

\footnotetext{
${ }^{1}$ Eng. Agr. MSc Doutorando, Dep. De Agricultura FCA/Unesp, Fazenda Experimental Lageado, Caixa Postal 237, 18603-970, Botucatu-SP, ferdinando.silva@yahoo.com.br;

${ }^{2}$ Prof. Dr., Depto. de Agricultura, FCA/Unesp, Fazenda Experimental Lageado, Caixa Postal 237, 18603-970, Botucatu-SP;

${ }^{3}$ Eng. Agr. Dr., Milenia Agrociências S.A., Uberlândia-MG;

${ }^{4}$ Eng.Agr. Dr., Depto. de Agricultura, FCA/Unesp, Fazenda Experimental Lageado, Caixa Postal 237, 18603-970, Botucatu-SP
} 
sprouting) and five rates of glyphosate: $0,180,360,720$ and $1440 \mathrm{~g}$ a e ha ${ }^{-1}$, applied to $C$. rotudus at the pre-flowering. At 30 days after glyphosate application the tubers were collected for evaluation by tetrazolium test and sprouting. The concentration of tetrazolium used for validation was $1 \%$, keeping the tubers in the solution for a period of 24 hours. At the end of each studied period, the tubers were removed, washed and cut to conduct visual assessment, determining the presence and intensity of coloration along the surface of them. The best treatments were those in which the tubers were previously dehydrated, indicating that tetrazolium entrance predominantly occurs by mass flow. The treatments results for methodology validation indicated that the coloration percentage decreased as the glyphosate rates increased. Tetrazolium test is a good indicator of the viability of purple nutsedge tubers, with satisfactory results when immersed in $1 \%$ concentration for at least 8 hours.

Key-words: Weed, tetrazolium, purple nutsedge.

\section{Introdução}

A tiririca é a planta daninha mais disseminada e a mais nociva do mundo, sendo encontrada no Brasil em diversos agroecossistemas (Lorenzi, 2000). Segundo Durigan et al. (2006), a tiririca é uma planta daninha de difícil erradicação e, por conseqüência, as áreas agrícolas infestadas com esta espécie crescem continuamente em curto espaço de tempo.

Hernandez et al. (2001) citam que o principal método de controle das plantas daninhas é o químico, por meio da aplicação de herbicidas, tanto na condição de préemergência como de pós-emergência dessas plantas. No entanto, para se obter um bom controle, é necessário o conhecimento da biologia da planta, pois com isso, é possível uma melhor escolha do herbicida a ser utilizado, a melhor época e o melhor tipo de aplicação, bem como o seu uso racional, obtendo o máximo de eficácia (Kogan, 1987).

Dentre os herbicidas, o glyphosate apresenta boa ação no controle da tiririca, pois pode translocar até os tubérculos próximos ao bulbo basal, proporcionando redução significativa na rebrota após sua aplicação (Freitas et al., 1997).
O desenvolvimento de testes rápidos, visando a determinação da qualidade fisiológica das sementes, tem sido um dos principais objetivos dos tecnólogos de sementes há vários anos, principalmente a partir do final do século XIX, quando o sistema de produção de sementes começou a ser organizado em diversos países da Europa (Bittencourt, 1995).

Dentro do sistema de produção de sementes, a precisão e rapidez das informações são fundamentais para auxiliar nas tomadas de decisão. Nesse sentido, o teste de tetrazólio tem se destacado nos programas de controle de qualidade de sementes de soja, devido à rapidez e eficiência na determinação da viabilidade, do vigor e das principais causas de perda de qualidade destas sementes (França Neto, 1994).

O teste de tetrazólio baseia-se na atividade das enzimas desidrogenases, que atuam na glicólise e ciclo de Krebs. Estas enzimas, particularmente a desidrogenase do ácido málico, catalisam a reação de redução do sal de tetrazólio (2,3,4-trifenil cloreto de tetrazólio) nas células vivas. Quando a semente é imersa na solução de tetrazólio, esta se difunde através dos tecidos, ocorrendo a reação de redução que resulta na formação de um 
composto vermelho não difusível, conhecido por formazan (França Neto et al., 1988).

Para Botezelli (1998), o teste que utiliza o tetrazólio é classificado como indireto na avaliação dessa viabilidade e rápido na estimativa antecipada da germinação, apresentando excelentes condições para aplicação de rotina, principalmente para espécies com tempo de germinação prolongada.

No Brasil, a metodologia do teste de tetrazólio é conhecida há aproximadamente, vinte e cinco anos (Costa \& Marcos Filho, 1994). No entanto, a adoção deste para outras espécies, no nível de detalhes que se faz para a soja, ainda é incipiente, limitando-se à avaliação da viabilidade das sementes (Krzyzanowski \& França Neto, 1991), embora sua potencialidade apresente bom nível de exatidão e confiança. Resultados obtidos em testes de referência, junto a laboratórios de sementes (França Neto et al., 1986), possibilitaram verificar que o tetrazólio foi o segundo teste mais preciso, classificado logo após o teste padrão de germinação, levando-se em conta a consistência dos resultados.

O objetivo deste trabalho foi conciliar as vantagens do teste de tetrazólio no desenvolvimento e validação de uma metodologia eficaz na avaliação da viabilidade de tubérculos de tiririca (Cyperus rotundus), permitindo, assim, obter resultados mais confiáveis.

\section{Material e Métodos}

O trabalho foi conduzido no Núcleo de Pesquisas Avançadas em Matologia (NuPAM), da FCA / UNESP, campus de Botucatu - SP. O produto químico utilizado foi o cloreto de 2,3,5 trifeniltetrazólio (denominado neste trabalho apenas como tetrazólio).

$\mathrm{O}$ delineamento experimental foi inteiramente casualizado com 60 tratamentos e quatro repetições com cinco tubérculos de $C$. rotundus cada. As unidades experimentais foram constituídas por copos plásticos de 200 $\mathrm{mL}$, nos quais os tubérculos foram colocados inteiros juntamente com $50 \mathrm{~mL}$ da solução de tetrazólio. Os tratamentos foram combinados em esquema fatorial $3 \times 4 \times 5$, sendo três condições: tubérculos mortos (como testemunha), condicionamento com água e condicionamento com desidratação; quatro concentrações de tetrazólio: 0,$1 ; 0,25 ; 0,5$ e 1\%; e cinco períodos de avaliação: $8,16,24$, 32 e 48 horas após imersão na solução.

O condicionamento com água correspondeu a imersão dos tubérculos em água destilada por um período de 12 horas antes de serem colocados em contato com a solução de tetrazólio, conforme sugerido por Delouche et al. (1976). No condicionamento com desidratação, os tubérculos foram mantidos sob temperatura ambiente até perderem $15 \%$ de umidade, antes de serem colocados em contato com a solução de tetrazólio. As testemunhas eram constituídas por tubérculos mortos, colocados nas respectivas concentrações de tetrazólio, nos diferentes períodos de avaliação, permitindo, assim observar e comparar a ação do tetrazólio.

Após imersão na solução, os tubérculos eram mantidos em germinador com temperatura constante de $35^{\circ} \mathrm{C}$ em ausência de luz. Ao término de cada período estudado, os tubérculos eram retirados da solução de tetrazólio, lavados em água corrente e cortados longitudinalmente, para que fosse procedida a avaliação visual, determinando-se a presença e intensidade de coloração ao longo da superfície do tubérculo. Para a observação externa das gemas, foi utilizado um procedimento com uso de ácido sulfúrico para a remoção química da camada mais externa dos tubérculos, permitindo a clara visualização das gemas viáveis coloridas. 
Foi criada uma escala de coloração baseada nos resultados encontrados, para auxiliar na avaliação dos tratamentos para o desenvolvimento da metodologia, conforme Figura 1. Por meio desta escala, os tubérculos receberam notas entre 1 e 5 , sendo que, 1 representa nenhuma coloração e 5 coloração total e intensa na região central e das gemas do tubérculo.

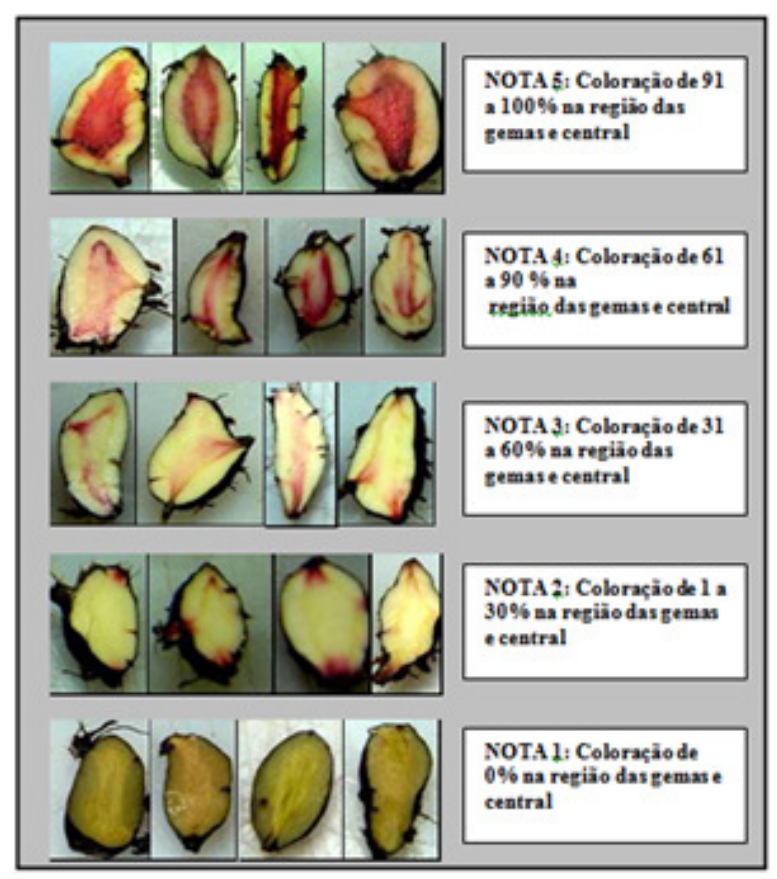

Figura 1. Escala de coloração dos tubérculos.

Para a validação da metodologia, utilizou-se delineamento experimental inteiramente casualizado, com 10 tratamentos e quatro repetições. Os tratamentos foram combinados em esquema fatorial $2 \times 5$, sendo dois métodos para avaliação dos tubérculos: teste com tetrazólio e teste de brotação; e cinco doses de glyphosate: $0,180,360,720$ e $1440 \mathrm{~g}$ e.a. $\mathrm{ha}^{-1}$. O glyphosate foi utilizado por translocar na cadeia de tubérculos e dependendo da dose matar os mesmos, sendo essa diferença de controle e morte dos tubérculos importante na utilização da viabilidade da metodologia.
Foram plantados seis tubérculos de $C$. rotundus em vasos com capacidade para dois litros de solo, os quais foram preenchidos com Latossolo Vermelho distrófico (LVd). O glyphosate foi aplicado nos vasos infestados com tiririca no estádio de pré-florescimento, por ser a época que afeta a maior porcentagem de tubérculos (Durigan et al., 2005). Um mês após a aplicação, os tubérculos foram coletados para as avaliações pelos testes com tetrazólio e brotação.

O herbicida foi aplicado com pulverização constituída por quatro pontas de pulverização XR $11002 \mathrm{VS}$, espaçadas de 0,5 $\mathrm{m}$ e posicionadas a $0,5 \mathrm{~m}$ de altura em relação à superfície das unidades experimentais. Foi utilizado pulverizador costal, pressurizado por ar comprimido, com pressão constante de 2 bar com volume de aplicação correspondente a 200 $\mathrm{L} \mathrm{ha}^{-1}$.

Para o teste com tetrazólio os tubérculos coletados passaram por condicionamento de desidratação. A concentração da solução de tetrazólio foi de $1 \%$, mantendo os tubérculos nesta solução por um período de 24 horas. Os tubérculos foram colocados em copos plásticos de $200 \mathrm{~mL}$ com uma quantidade suficiente da solução de tetrazólio para cobri-los. Passadas as 24 horas, os tubérculos foram retirados dos copos, lavados em água corrente e cortados longitudinalmente para que fosse procedida a avaliação visual, determinando-se a presença e intensidade de coloração ao longo da superfície do tubérculo, obtendo assim, a porcentagem de tubérculos coloridos e conseqüentemente viáveis

Para o teste de brotação os tubérculos foram mantidos em vasos com areia lavada e esterilizada com $60 \%$ da capacidade de campo. Os vasos foram incubados em ausência de luz a uma temperatura média de $26^{\circ} \mathrm{C}$. Os resultados foram apresentados em porcentagem de brotação. 
Os dados da porcentagem de brotação e de tubérculos coloridos foram analisados com auxílio do teste "t" a nível de $10 \%$ de probabilidade.

\section{Resultados e Discussão}

Pelos resultados obtidos fica evidente que os tratamentos que sofreram desidratação, apresentaram melhores resultados comparandose com os tubérculos que sofreram o condicionamento com água, os, como pode ser observado na Figura 2. As notas para os tubérculos que sofreram condicionamento com água não passaram de 2 , enquanto que os tubérculos desidratados atingiram notas 5 . Portanto, apesar de Delouche et al. (1976) recomendar o condicionamento para sementes, mantendo-as imersas em água, na tentativa de obtenção de melhores resultados na coloração com tetrazólio, o mesmo não se aplica para os tubérculos de C. rotundus, onde os tubérculos que foram desidratadas apresentaram coloração vermelho-púrpura mais clara (Figura 2 e 5) e com maior intensidade.

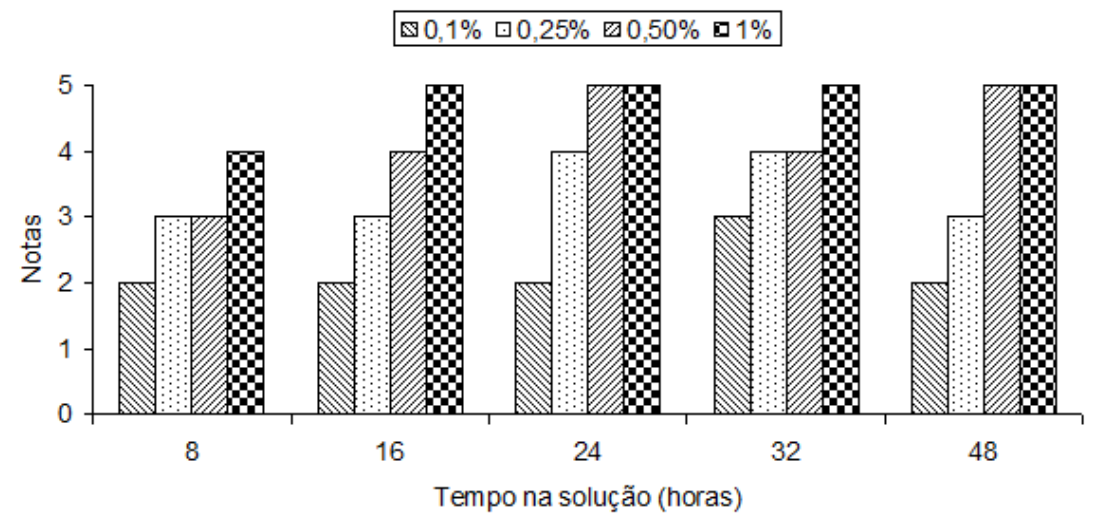

Figura 2. Notas dos tratamentos que sofreram condicionamento de desidratação, em função do período de permanência na solução (horas) e da concentração da solução de tetrazólio (\%).

Os resultados indicam que a perda de umidade antecedendo o teste foi fundamental para o desenvolvimento de coloração vermelho mais intenso indicando, possivelmente, que o tetrazólio é absorvido pelo tubérculo por fluxo de massa, ou seja, é carregado ao interior destas estruturas pelo fluxo de água durante o processo de reidratação. Foi possível observar também que o tamanho do tubérculo não interferiu nos resultados de coloração.

Observou-se que com o aumento da concentração do tetrazólio há uma maior e melhor coloração do tubérculo e o mesmo ocorre quando aumenta-se o período de exposição do tubérculo à solução de tetrazólio. O aumento da imersão até 24 horas intensificou a coloração dos tubérculos previamente desidratados, em todas as concentrações. Mas em casos como na concentração de $0,1 \%$, com condicionamento por desidratação, mesmo mantendo o tubérculo em contato por 48 horas este não apresentou uma coloração satisfatória, recebendo nota 2 , enquanto que os tubérculos que permaneceram nesta mesma concentração por um período de 32 horas receberam nota 3 , que corresponde a maior nota nesta concentração, mostrando que a melhor 
coloração não ocorre necessariamente no maior período de tempo (Figuras 2 e 3).

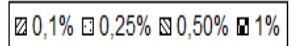

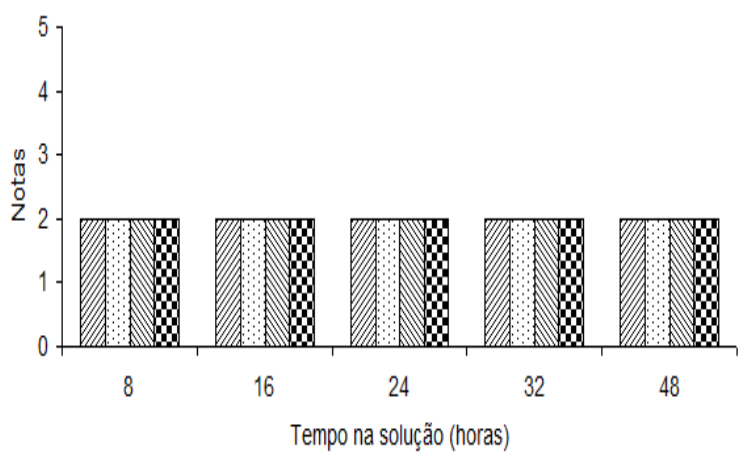

Figura 3. Notas dos tratamentos que sofreram condicionamento com água, em função do período de permanência na solução (horas) e da concentração da solução de tetrazólio (\%).

Como pode-se observar nas Figuras 2 e 3 , em todos os tratamentos que receberam as maiores notas os tubérculos que sofreram desidratação. $O$ tratamento com a maior concentração de tetrazólio (1\%), 8 horas na solução e condicionamento por desidratação, possibilitou uma boa coloração num curto período de tempo. Os tratamentos nas concentrações de 0,25 e $0,5 \%$, nos períodos de 24 e 16 horas respectivamente também proporcionaram boa coloração dos tubérculos em baixas concentrações. Os tubérculos mortos, utilizados como testemunha não

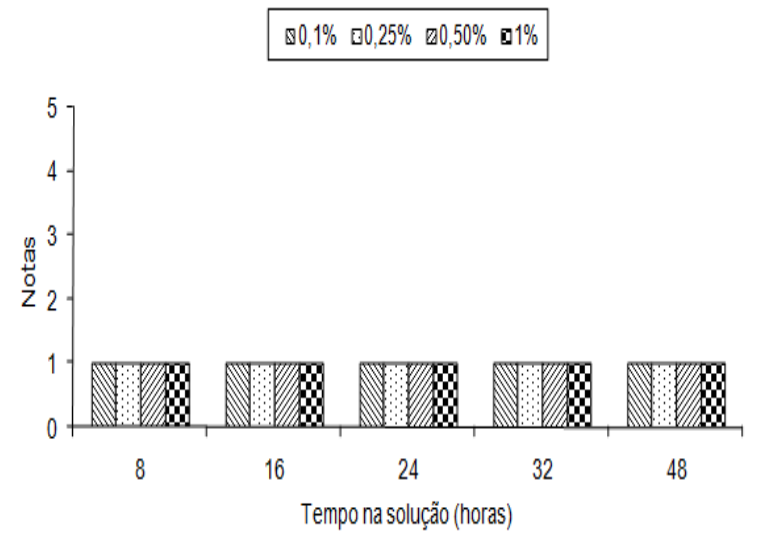

Figura 4. Notas das testemunhas, em função do período de permanência na solução (horas) e da concentração da solução de tetrazólio (\%).

apresentaram coloração, recebendo nota 1, conforme observado na Figura 4.

Por meio da Figura 6, observa-se o efeito positivo do aumento da concentração do Tetrazólio na maior e melhor coloração do tubérculo. O mesmo efeito positivo foi observado no aumento do período de incubação (Figura 7). A partir destes dados, presume-se que a concentração de $0,1 \%$ de Tetrazólio é muito baixa para o estudo nestas condições, pois não apresentou coloração satisfatória. 


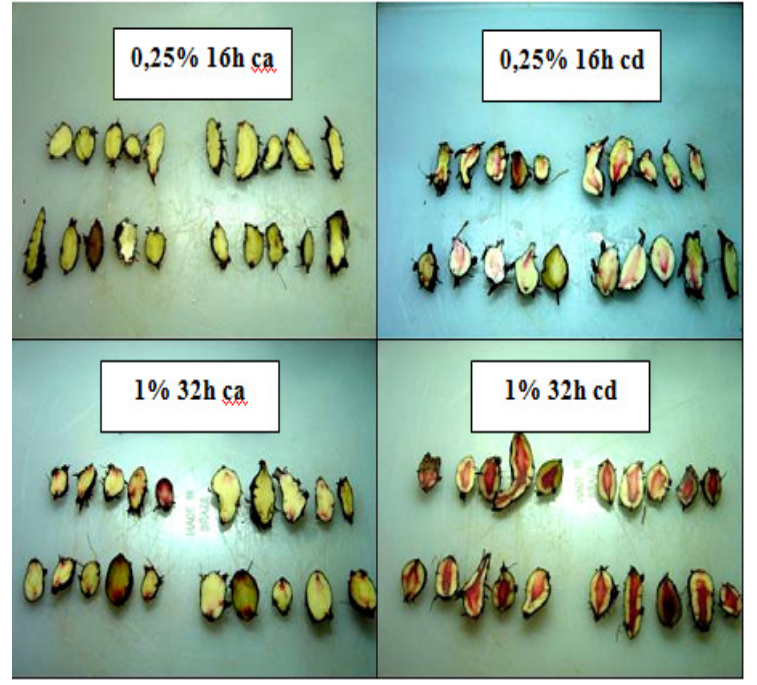

Figura 5. Tratamentos com $0,25 \%$ e $1 \%$ de Tetrazólio, período de 16 e 32 horas na solução, condicionamento com água (ca) e desidratação (cd).

Esta metodologia para coloração dos tubérculos, associada ao tratamento com ácido sulfúrico, também permite avaliar o número de gemas presente nos tubérculos, já que o

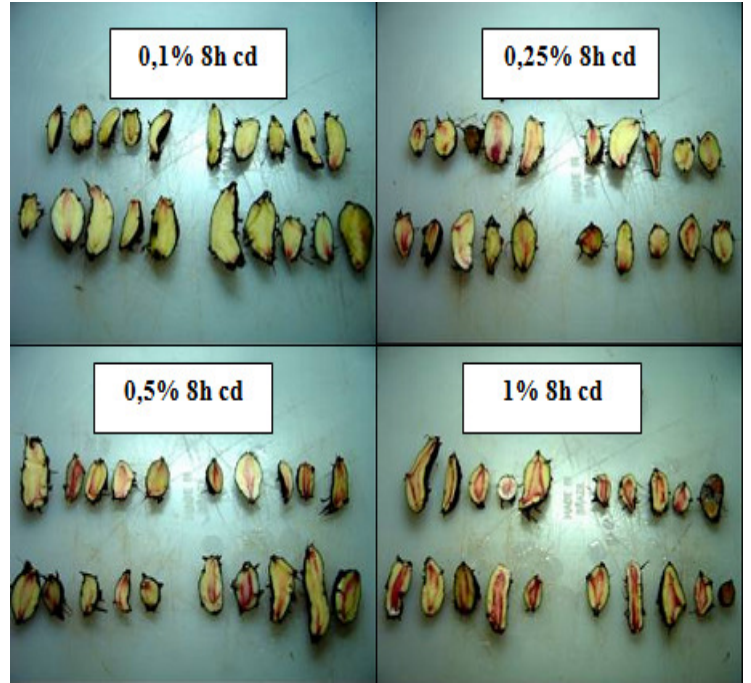

Figura 6. Tratamentos condicionado para desidratação (cd), 8 horas na solução, nas concentrações de 0,$1 ; 0,25 ; 0,5 ;$ e $1 \%$ de Tetrazólio.

tetrazólio é absorvido ou translocado por estas gemas, apresentando assim uma coloração passível de ser observada (Figura 8).

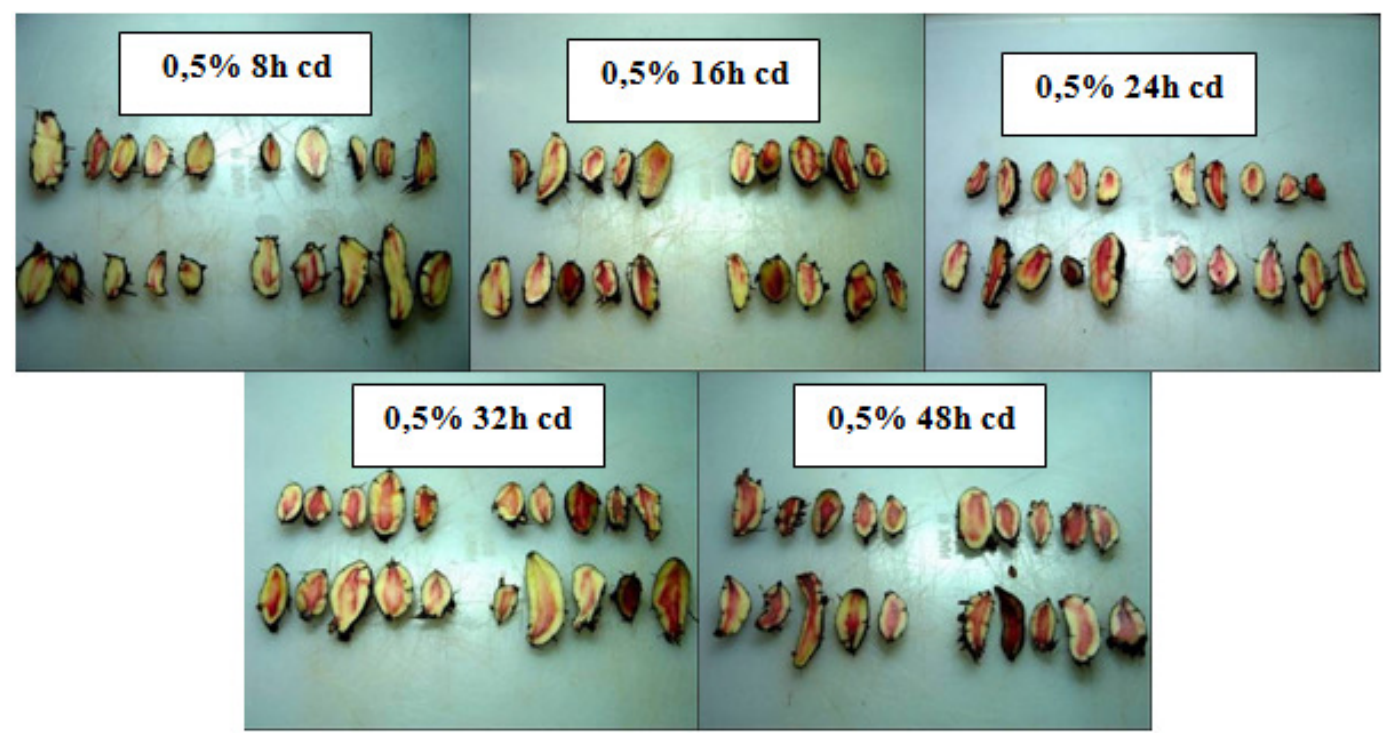

Figura 7. Tratamentos condicionados para desidratação (cd), na concentração de $0,5 \%$ de Tetrazólio, nos períodos de 8, 16, 24, 32 e 48 horas. 


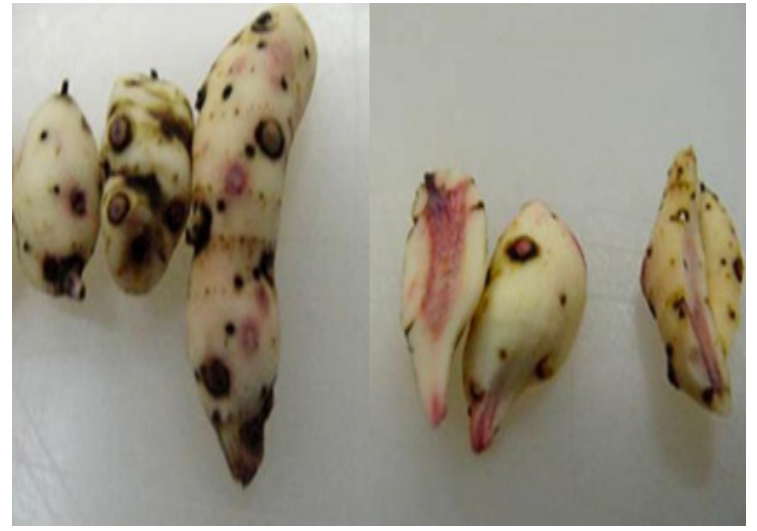

Figura 8. Detalhe das gemas tratadas com tetrazólio e limpas com ácido sulfúrico.

$\mathrm{Na}$ validação da metodologia, os resultados de coloração obtidos com o teste de tetrazólio, apresentados na Tabela 1, demonstram que a porcentagem de tubérculos coloridos pelo tetrazólio variou entre 74,35 e $87,70 \%$, correspondendo respectivamente à maior dose de glyphosate e à testemunha, sendo a maior dose de glyphosate a única a diferir significativamente da testemunha. Sendo a dose de 1440 g e.a. ha ${ }^{-1}$ de glyphosate a que matou a maior parte de tubérculos apresentando diferença estatística na porcentagem de coloração quando comparado com tratamento sem aplicação do herbicida.

Na Tabela 1, estão apresentados os resultados do teste de brotação e observa-se que à medida que aumenta a dose do glyphosate o percentual de brotação decresce, mostrando o efeito do herbicida sobre a brotação dos tubérculos.

Tabela 1. Porcentagem de coloração dos tubérculos e brotação de $C$. rotundus após aplicação do herbicida glyphosate em diferentes doses.

\begin{tabular}{|c|c|c|c|}
\hline Tratamentos & Dose (g e.a. ha ${ }^{-1}$ ) & Tubérculos coloridos(\%) & Brotação (\%) \\
\hline 1 - Testemunha & - & 87,69 a & $93,03 \quad \mathrm{a}$ \\
\hline 2 - glyphosate & 180,0 & 84,57 a & 76,27 \\
\hline 3 - glyphosate & 360,0 & 85,04 a & $64,36 \quad b$ \\
\hline 4 - glyphosate & 720,0 & 87,47 a & 36,94 \\
\hline 5 - glyphosate & 1440,0 & $74,35 \quad b$ & $20,92 d$ \\
\hline $\mathrm{F}$ & & $1,81^{*}$ & $24,31^{*}$ \\
\hline $\mathrm{CV}(\%)$ & & 9,73 & 20,34 \\
\hline DMS & & 10,11 & 14,70 \\
\hline
\end{tabular}

Médias seguidas de mesma letra não diferem significativamente entre si pelo teste " $t$ " ao nível de 10\% de probabilidade.

O cruzamento dos dados dos testes de brotação e tetrazólio permitem supor que o baixo percentual de brotação, apesar do alto percentual de coloração, pode estar relacionado à dormência induzida pela translocação de subdoses de glyphosate até os tubérculos, hipótese que também foi sugerida por Jakelaitis et al. (2003). O glyphosate também apresentou efeito no número de tubérculos produzidos, apresentando redução na quantidade dos tubérculos à medida que se aumenta a dose do herbicida, conforme Tabela 1 e Figura 9. 


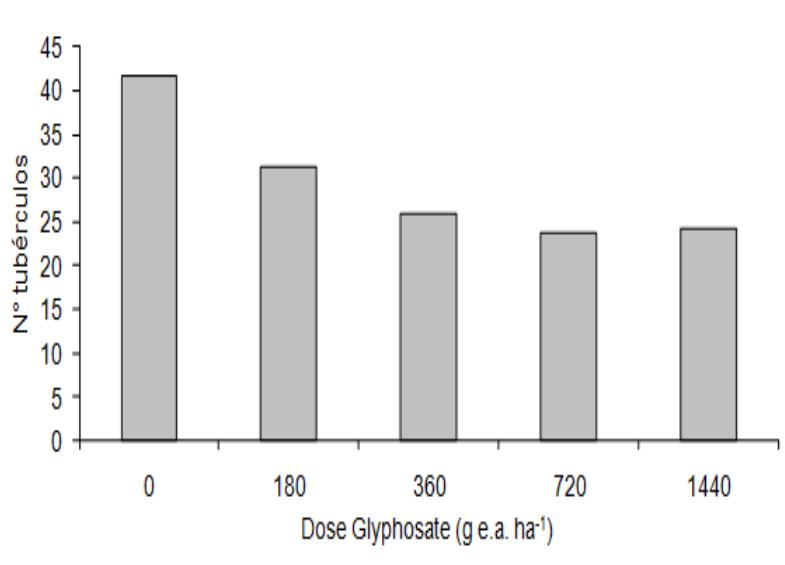

Figura 9. Número médio de tubérculos de $C$. rotundus produzidos em função da dose do herbicida glyphosate, 30 dias após a aplicação do herbicida.

\section{Conclusões}

Conclui-se que a desidratação dos tubérculos antes de serem colocados na solução de tetrazólio é fundamental para uma melhor coloração num menor período de tempo. A concentração de $0,1 \%$ de tetrazólio é muito baixa para o estudo nestas condições e a solução de $1 \%$ já apresenta bons resultados a partir de 8 horas de permanência dos tubérculos na solução, independente do tamanho dos mesmos. O teste de tetrazólio é um bom indicador da viabilidade de tubérculos de tiririca, indicando inclusive tubérculos dormentes. Mas exige-se o uso de testes complementares para avaliar, efetivamente, a porcentagem de brotação, uma vez que, mesmo tubérculos com intensa coloração podem se manter dormentes.

\section{Agradecimentos}

À FAPESP, Fundação de Amparo à Pesquisa do Estado de São Paulo, pelo apoio financeiro recebido.

\section{Referências}

BITTENCOURT, S.R.M. Avaliação da qualidade fisiológica de sementes de amendoim através do teste de tetrazólio. 1995. 111 f. (Dissertação-Mestrado em Fitotecnia) - FCAV / UNESP, Jaboticabal, SP, 1995.

BOTEZELLI, L. Influência de ambientes e embalagens de armazenamento sobre a viabilidade e o vigor de sementes de baru (Dipterys alata Vorgel). 1998. $70 \quad \mathrm{f}$. Dissertação (Mestrado em Fitotecnia) Universidade Federal de Lavras, Lavras, MG, 1998.

COSTA, N.P.; MARCOS FILHO, J. O emprego do teste de tetrazólio na avaliação da qualidade da semente de soja. Inf. ABRATES, Brasília, v.4, n.2, p. 53-63, 1994.

DELOUCHE, J.C. et al. O teste de tetrazólio para viabilidade da semente. Brasília: AGIPLAN, 1976. 103p.

DURIGAN, J.C.; TIMOSSI, P.C.; CORREIA, N.M. Manejo integrado da tiririca na produtividade de cana-de-açúcar. Planta Daninha, v.24, n.1, p.77-81, 2006.

DURIGAN, J. C.; CORREIA, N. M.; TIMOSSI, P. C. Estádios de desenvolvimento e vias de contato e absorção dos herbicidas na inviabilização de tubérculos de Cyperus rotundus. Planta Daninha, v.23, n.4, p.621626, 2005.

FRANÇA NETO, J.B. O teste de tetrazólio em sementes de soja. In: VIEIRA, R.D.; CARVALHO, N.M. (Eds.) Testes de vigor em sementes. Jaboticabal: FUNEP, 1994. p. 87-102.

FRANÇA NETO, J.B. et al. Soybean seed quality reference test in Brasil. Proc. Assoc. Off. Seed Analysts, v.60, n.3, p.17, 1986.

FRANÇA NETO, J.B. et al. Metodologia do teste de tetrazólio em sementes de soja. 
Londrina: EMBRAPA / CNPSo, 1988. 37p. (Circular Técnica, 32).

FREITAS, R.S. et al. Efeitos do flazassulfuron e do glyphosate em aplicações única e seqüencial sobre o controle da tiririca (Cyperus rotundus). Ceres, v.44, n.256, p.597603, 1997.

HERNANDEZ, D.D. et al. Influência do resíduo de colheita de cana-de-açúcar sem queima sobre a eficiência do imazapic e imazapic + pendimethalin. Planta Daninha, v.19, n.3, p. 419-426, 2001.

JAKELAITIS, A. et al. Efeitos de sistema de manejo sobre a população de tiririca. Planta Daninha, v.21, n.1, p.89-95, 2003.

KOGAN, M.A Ecofisiologia da tiririca, sua competição e efeitos alelopáticos com canade-açúcar. In: Eptam Herbicida Seletivo. Campinas: Stauffer Produtos Químicos, 1987. p. 1-7.

KRYZANOWSKI, F.C.; FRANÇA NETO, J.B. Situação atual de testes de vigor como rotina em programas de sementes no Brasil. Inf. ABRATES, v.1, n.3, p. 42-53, 1991.

LORENZI, H. Plantas daninhas do Brasil: terrestres, aquáticas, parasitas e tóxicas. 3. ed. Nova Odessa: Plantarum, 2000. 608 p. 